\title{
Article \\ Exploring the Genetic Diversity among Weedy Rice Accessions Differing in Herbicide Tolerance and Allelopathic Potential
}

\author{
Swati Shrestha ${ }^{1}$, Gourav Sharma ${ }^{1}$, Shandrea Stallworth ${ }^{1}{ }^{\mathbb{D}}$, Edilberto D. Redona ${ }^{2}$ and Te Ming Tseng ${ }^{1, * \mathbb{D}}$ \\ 1 Department of Plant and Soil Sciences, Mississippi State University, Starkville, MS 39762, USA; \\ s.shrestha@ufl.edu (S.S.); gourav1@vt.edu (G.S.); shandrea.stallworth@corteva.com (S.S.) \\ 2 Agronomy-Plant Breeding, Delta Research and Extension Center, Mississippi State University, \\ Stoneville, MS 38776, USA; edredona@drec.msstate.edu \\ * Correspondence: tt1024@msstate.edu
}

Citation: Shrestha, S.; Sharma, G.; Stallworth, S.; Redona, E.D.; Tseng, T.M. Exploring the Genetic Diversity among Weedy Rice Accessions

Differing in Herbicide Tolerance and Allelopathic Potential. Diversity 2022, 14, 44. https://doi.org/10.3390/ d14010044

Academic Editor: Ilias Travlos

Received: 8 December 2021

Accepted: 8 January 2022

Published: 11 January 2022

Publisher's Note: MDPI stays neutral with regard to jurisdictional claims in published maps and institutional affiliations.

Copyright: (c) 2022 by the authors. Licensee MDPI, Basel, Switzerland This article is an open access article distributed under the terms and conditions of the Creative Commons Attribution (CC BY) license (https:// creativecommons.org/licenses/by/ $4.0 /)$.

\begin{abstract}
Increasing agricultural productivity is indispensable to meet future food demand. Crop improvement programs rely heavily on genetic diversity. The success of weeds in the ecosystem can be attributed to genetic diversity and plasticity. Weedy rice, a major weed of rice, has diverse morphology and phenology, implying wide genetic diversity. Study was conducted to genotype weedy rice accessions $(n=54)$ previously phenotyped for herbicide tolerance and allelopathic potential using 30 SSR markers. Cultivated rice (CL163, REX) and allelopathic rice (RONDO, PI312777, PI338047) were also included in the study. Nei's genetic diversity among weedy rice (0.45) was found to be higher than cultivated rice (0.24) but less than allelopathic rice (0.56). The genetic relationship and population structure based on herbicide tolerance and allelopathic potential were evaluated. Herbicide-tolerant and susceptible accessions formed distinct clusters in the dendrogram, indicating their genetic variation, whereas no distinction was observed between allelopathic and non-allelopathic weedy rice accessions. Weedy rice accession B2, which was previously reported to have high allelopathy and herbicide tolerance, was genetically distinct from other weedy rice. Results from the study will help leverage weedy rice for rice improvement programs as both rice and weedy rice are closely related, thus having a low breeding barrier.
\end{abstract}

Keywords: crop-improvement; population genetics; weed suppression; sustainable weed management; palmer amaranth; glyphosate

\section{Introduction}

Commercial rice production in the US started in $1650^{\prime}$ s and extended towards South America in the eighteenth century [1]. According to Allston (1846), weedy rice was introduced as a contaminant from Asia in 1846 and since then has been affecting US rice production [2]. Weedy rice belongs to the same genus and species as the cultivated rice [3], limiting the use of chemical control, as both the rice plants and weedy rice are susceptible to herbicides with the same mode of action. Weedy rice may be controlled using crop rotation with soybean, sorghum, maize, and other cultural practices like winter flooding and fallow tillage $[4,5]$. However, the popularity of rice monoculture among farmers in major rice growing areas makes the infestation of weedy rice more severe year after year. Further, with the widespread adoption of Clearfield ${ }^{\mathrm{TM}}$ rice, gene flow among the weedy rice and herbicide-tolerant Clearfield rice has been reported, complicating weedy rice management $[6,7]$. The average economic loss in rice due to weedy rice is $274 \$ /$ ha in Arkansas, USA [4].

Weedy rice infesting rice fields are genetically and morphologically diverse [8-10]. Weedy rice of diverse hull color (straw, black, brown, gold, gray), awn length, variable flag leaf length, and different maturity period are present [11]. Weedy rice also has higher shattering and variable dormancy [12]. These morphological variations in weedy rice can 
be attributed to their wide genetic variation. For example, Shivrain et al. (2010a) reported that black hull, brown hull, and straw hull weedy rice accessions are genetically diverse, with Nei's genetic diversity of 0.7 and weedy have higher genetic variation than cultivated rice [8]. Cao et al. (2006) reported that weedy rice from China have very high genetic diversity with heterozygosity of 0.313 and Shannon's diversity index of 0.572 [13]. High genetic diversity in the weedy rice, which corresponds to greater morphological variation, has pros and cons. Although the robust nature of weedy rice makes them one of the most difficult weeds to control, understanding the genetic basis of their robustness would provide valuable resources for crop improvement programs.

Weedy rice accessions have been evaluated morphologically and genetically for numerous biotic and abiotic stress tolerances. For example, 28 blast-resistant QTL were identified in two weedy rice accessions by Liu et al. (2015), which can be used in rice breeding programs to develop blast tolerant rice cultivars [14]. Ziska and Mc. Clung (2008) reported higher biomass (55\%) and leaf area $(62 \%)$ of weedy rice than the cultivated rice under elevated carbon dioxide conditions, indicating the ability of weedy rice to survive efficiently in the face of climate change and global warming [15].

Natural potential of plants to influence growth of neighboring plants, a phenomenon known as allelopathy, has been explored in cultivated rice since 1980s but limited research has been conducted on allelopathic potential of weedy rice [16]. Studies have shown that some rice cultivars have innate allelopathic potential which differs depending on its source, plant size, developmental stage, plant part used, and hull color $[17,18]$. Rice root exudates, rice straw (left in the field after harvest), and rice leaves, contain allelochemicals, such as momilactone, that suppress some weed species in rice fields $[17,18]$. Morphological screening of fifty-four weedy rice accessions from Arkansas, USA, showed that two weedy rice genotypes (B2 and $\mathrm{B} 81$ ) had higher allelopathic potential against barnyardgrass and Amazon sprangletop, and six weedy rice genotypes (B20, B2, S11, B49, B51, S59) had reduced sensitivity to glyphosate and flumioxazin $[16,19]$. These 54 weedy rice accessions were selected from larger pool of 208 weedy rice accessions collected from all the major rice growing regions or Arkansas based on their competitive traits including early flowering, high shattering, high plant biomass and high grain yield [20]. However, to the best of our knowledge, the genetic diversity in these weedy rice accession has not been explored. To determine an association between the phenotypic and genetic diversity among these weedy rice accessions from Arkansas, a study was conducted to evaluate genetic diversity in the fifty-four accessions using 30 SSR markers.

\section{Materials and Methods}

\subsection{Plant Material and Genomic DNA Extraction}

Seeds of 54 different weedy rice accessions previously characterized for herbicide response (glyphosate and flumioxazin) and allelopathic potential against weed species (barnyardgrass and Amazon sprangletop) were obtained from Dr. Burgos lab in Arkansas [16,17] (Supplementary Table S1). Seeds of commercial rice cultivars CL163 and REX were obtained from Dr. Redona's lab in Delta Research and Extension Centre, Stoneville, MS, USA, and seeds of allelopathic rice were provided by Dr. Gealy from Dale Bumpers National Rice Research Centre, Stuttgart, AR, USA.

For DNA extraction, fresh tissues were collected from young leaves of 5-week old plants grown in the greenhouse. For each biotype, three plants were grown and leaf tissue was collected from each plant to serve as biological replicate in the diversity study. The pots were placed randomly in the greenhouse to minimize the environmental effect during the study. The experimental setup in the greenhouse was completely randomized design. The tissues were stored at $-80{ }^{\circ} \mathrm{C}$ overnight after collection, and DNA was extracted from each sample (three replicate for each biotype) using the CTAB method with slight modifications [21]. The quality and quantity of DNA were calculated using Nanodrop 2000 spectrophotometer. Extracted DNA was stored at $-20^{\circ} \mathrm{C}$ until PCR amplification. 


\subsection{Polymerase Chain Reaction (PCR) Using Simple Sequence Repeat (SSR) Markers}

The DNA samples were diluted to $100 \mathrm{ng} / \mu \mathrm{L}$ before PCR. A total of $30 \mathrm{SSR}$ primers (Supplementary Table S2) from the standard panel of 50 developed by McCouch et al. (2002) available publicly in the rice Gramene marker database http:/ / archive.gramene.org/ markers/microsat/50_ssr.html (accessed on 16 January 2018) was used for accessing the genetic diversity of the accessions [22]. These markers can evaluate the genetic similarity and differences among the oryza species with AA genome [23]. PCR reactions were carried out in 96 well plates with $25 \mu \mathrm{L}$ reaction volume. The reaction mixture consisted of $12.5 \mu \mathrm{L}$ of PCR master mix (Taq polymerase, dATP, dGTP, dCTP, dTTP, $\mathrm{MgCl}_{2}$ ), forward primer $1 \mu \mathrm{L}$, reverse primer $2 \mu \mathrm{L}$, DNA $1 \mu \mathrm{L}$ and $8.5 \mu \mathrm{L}$ of nuclease-free water. PCR profile used for DNA amplification was (i) Denaturation at $94{ }^{\circ} \mathrm{C}$ for $5 \mathrm{~min}$ (ii) 35 cycles of $94{ }^{\circ} \mathrm{C}$ for $1 \mathrm{~min}$ followed by annealing temperature from $55^{\circ} \mathrm{C}$ to $67^{\circ} \mathrm{C}$, which was marker dependent (iii) final extension at $72{ }^{\circ} \mathrm{C}$ for $5 \mathrm{~min}$. PCR products were separated in $6 \%$ polyacrylamide gels for $45 \mathrm{~min}$ at 180 volts and stained with $0.05 \%$ ethidium bromide. Stained gels were visualized under a UV trans-illuminator and photographed with a camera.

\subsection{Data Analysis}

Individual bands were considered as co-dominant markers and scored using Cross Checker 2.91 developed by Dr. J.B Buntjier 1999 [24]. The bands were scored as binary characters, with 1 for the presence of bands and 0 for the absence of bands to retain the allele information. POPGENE version 1.32 was used to obtain the number of alleles per locus (A), percentage of polymorphic loci (P), genetic distance (D), Nei's gene diversity (h), and Shannon's index (I) using a data matrix from Cross Checker. Nei's genetic distance was used to develop a dendrogram with the UPGMA algorithm to evaluate the genetic relationship among the accessions. STRUCTURE 2.3.4 was used for analyzing the population structure of the accessions with the genetic data generated by microsatellite SSR markers [25]. The data was run in STRUCTURE from $K=1$ to $K=8$ with three iterations for each $K$ value and burn-in period of 100,000 and 500,000 replications. The best fit value of $\mathrm{K}$ was obtained using Structure Harvester, and Distruct was used for the diagrammatic representation of genetic data produced by STRUCTURE.

To determine the association between genotypes and herbicide tolerance, weedy rice accessions from Shrestha et al. (2019) with injury of less than $30 \%$ and more than $90 \%$ five weeks after treatment with glyphosate (1120 g a.i/ha) and/or flumioxazin (72 g a.i/ha) were selected for marker-trait association analysis. Likewise, to determine the association between weedy rice genotypes and their allelopathic potential, the most and least allelopathic weedy rice accessions (average growth inhibition of neighboring barnyardgrass and Amazon sprangletop by more than $45 \%$ and less than $20 \%$, respectively) identified in the study by Shrestha et al. (2020) were selected for analysis [16,17].

\section{Results}

\subsection{Genetic Diversity among Weedy Rice, Cultivated Rice, and Allelopathic Rice}

Analysis of the markers showed that the alleles per locus ranged from 2-3 with an average of 2.9. The overall Nei's gene diversity (h) among the weedy rice, cultivated rice, and allelopathic rice used in the study was 0.45 ; lowest gene diversity of 0.14 detected by markers RM162 and RM118 and highest gene diversity of 0.65 detected by RM338 (Table 1). Weedy rice cultivated rice and allelopathic rice had h-value of $0.4,0.24$, and 0.56 , respectively.

The mean Shannon Information Index (I) for the entire population was 0.74 , and it ranged from 1.06 to 0.02 . Higher the Shannon's Index, the greater is the genetic diversity in the population. Among the three groups, allelopathic rice had the highest I of 0.85 , and cultivated rice had the lowest I, with a value of 0.38 . Shannon's Information index for weedy rice was 0.66 , indicating these had higher genetic diversity than southern rice cultivars CL163 and REX. Dendrogram based on Nei's genetic distance clustered weedy rice and rice cultivars (CL163 and REX) in one group, and the allelopathic rice were clustered 
separately (Figure 1). The genetic distance between weedy rice and rice cultivar was 0.13 , and the genetic distance between weedy rice and allelopathic rice was 0.26.

Table 1. Genetic variation among the population (weedy rice, cultivated rice, and allelopathic rice) indicated through allele's number, Nei's gene diversity, and Shannon's Index.

\begin{tabular}{|c|c|c|c|c|}
\hline S1. No. & Marker & Observed Alleles & Nei's Gene Diversity & Shannon's Index \\
\hline 1 & RM495 & 3 & 0.3098 & 0.5837 \\
\hline 2 & RM283 & 3 & 0.6431 & 1.0647 \\
\hline 3 & RM237 & 3 & 0.4464 & 0.7578 \\
\hline 4 & RM431 & 3 & 0.6464 & 1.0660 \\
\hline 5 & RM154 & 2 & 0.4989 & 0.6921 \\
\hline 6 & RM452 & 2 & 0.1896 & 0.3382 \\
\hline 7 & OSR13 & 2 & 0.1896 & 0.3382 \\
\hline 8 & RM338 & 3 & 0.6561 & 1.0820 \\
\hline 9 & RM514 & 3 & 0.2690 & 0.4828 \\
\hline 10 & RM124 & 3 & 0.5059 & 0.7461 \\
\hline 11 & RM507 & 3 & 0.6358 & 1.0537 \\
\hline 12 & RM413 & 3 & 0.1714 & 0.3666 \\
\hline 13 & RM161 & 3 & 0.4464 & 0.7578 \\
\hline 14 & RM133 & 3 & 0.6358 & 1.0537 \\
\hline 15 & RM162 & 3 & 0.1470 & 0.3267 \\
\hline 16 & RM125 & 3 & 0.4464 & 0.7578 \\
\hline 17 & RM455 & 3 & 0.6445 & 1.0627 \\
\hline 18 & RM118 & 3 & 0.1470 & 0.3267 \\
\hline 19 & RM408 & 3 & 0.6259 & 1.0299 \\
\hline 20 & RM152 & 3 & 0.4579 & 0.7810 \\
\hline 21 & RM44 & 3 & 0.3098 & 0.5837 \\
\hline 21 & RM284 & 3 & 0.3527 & 0.6383 \\
\hline 23 & RM433 & 3 & 0.6358 & 1.0537 \\
\hline 24 & RM447 & 3 & 0.3250 & 0.6035 \\
\hline 25 & RM316 & 3 & 0.5240 & 0.8829 \\
\hline 26 & RM215 & 3 & 0.6445 & 1.0627 \\
\hline 27 & RM271 & 3 & 0.3415 & 0.6331 \\
\hline 28 & RM484 & 3 & 0.5240 & 0.8829 \\
\hline 29 & RM536 & 3 & 0.6445 & 1.0627 \\
\hline \multirow[t]{2}{*}{30} & RM277 & 3 & 0.3415 & 0.6331 \\
\hline & Mean & 2.9 & 0.44 & 0.75 \\
\hline
\end{tabular}

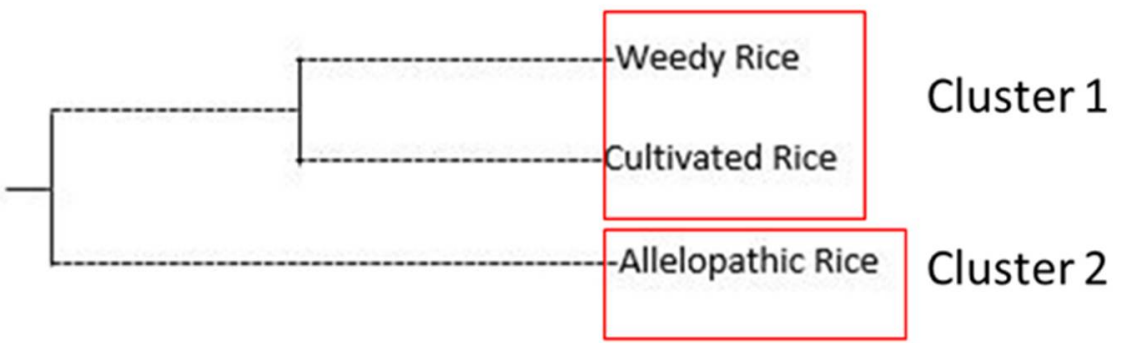

Figure 1. Dendrogram based on Nei's genetic distance indicating a genetic relationship between weedy rice, cultivated rice, and allelopathic rice. Based on Nei's genetic distance, weedy rice and cultivated rice clustered together (red box: cluster 1) and allelopathic rice (red box: cluster 2) clustered separately, indicating weedy rice and cultivated rice are more genetically similar as compared to the allelopathic rice used in the current study.

\subsection{Genetic Relationship and Differentiation Based on Herbicide Tolerance}

In this study, the herbicide (flumioxazin and glyphosate) tolerant and susceptible weedy rice accessions, previously described by Shrestha et al. 2019 were selected [17]. Commercial rice (CL163 and REX) which are highly susceptible to both glyphosate and flumioxazin with almost $100 \%$ injury 5 weeks after treatment with the herbicide were also included for comparison and considered as separate population (susceptible rice cultivars). The overall Nei's gene diversity among all the three populations was 0.47 , varying from 0.12 to 0.66 , and the Shannon's information index was 0.78 ranging from 0.2 to 1.09 . Dendrogram, 
based on Nei's genetic distance, divided the herbicide-tolerant and susceptible accessions into four different clusters (Figure 2). Weedy rice accession ALR4 whichwas reported to be most susceptible to glyphosate and flumioxazin by Shrestha et al. (2019), clustered together with rice cultivars CL163 and REX, which are also highly susceptible to both the herbicides indicating a higher level of genetic similarity among these genotypes [17]. Accession B2, which has been reported to be highly tolerant to glyphosate by Shrestha et al. (2019), was not grouped with other herbicide-tolerant/susceptible accessions and formed a distinct cluster by itself [17]. Cluster 3 consisted of all the glyphosate and flumioxazin susceptible accessions. In contrast, cluster 2 consisted of all the accessions tolerant to herbicides indicating, association of the markers with herbicide tolerance in the current population. Individuals belonging to the same clusters had lesser genetic distance than those belonging to different clusters. The grouping of the accessions was found to be associated with herbicide tolerance, and all the herbicide-tolerant and herbicide susceptible accessions were grouped separately, implying diverse genetic backgrounds of tolerant and susceptible accessions. Results from the STRUCTURE showed correlation with the PopGene data and divided the herbicide-tolerant and susceptible accessions into $K=4$ clusters, again inferring distinct clustering of accessions based on herbicide tolerance. Both black hull and straw hull herbicide-tolerant accessions showed similar coloring patterns in the figure obtained from Distruct, indicating a close genetic relationship among the weedy rice accessions in terms of herbicide tolerance irrespective of hull color (Figure 3). Likewise, both the black and straw hulled accessions susceptible to herbicides showed similarity in genetic makeup, indicating differential tolerance to herbicide is not associated with the morphological trait, hull color.

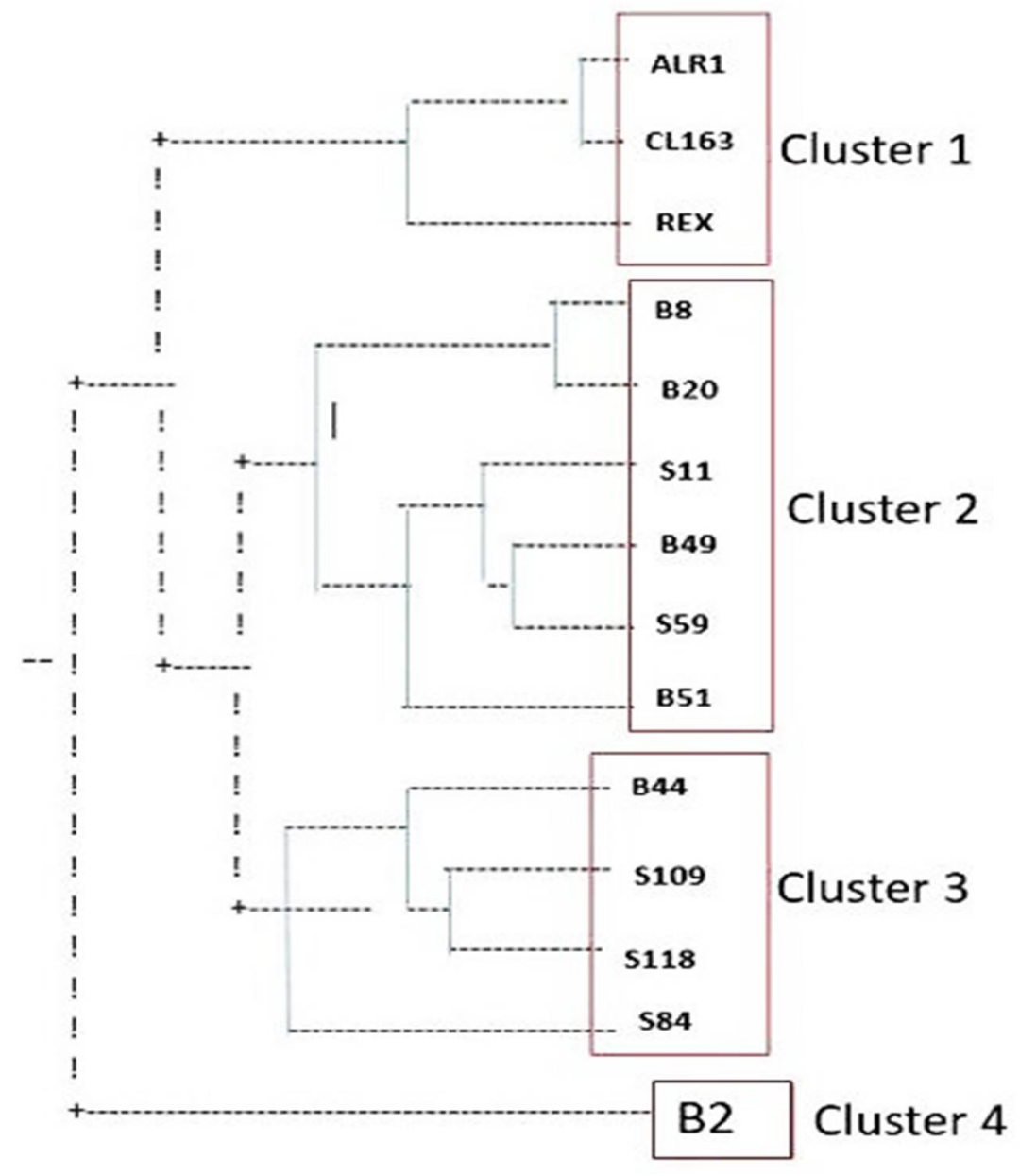

Figure 2. Dendrogram representing the relationship among the accessions with respect to herbicide tolerance. Accessions within the red box are more genetically similar as compared to accessions belonging to different red boxes, as indicated by Nei's genetic distance. 


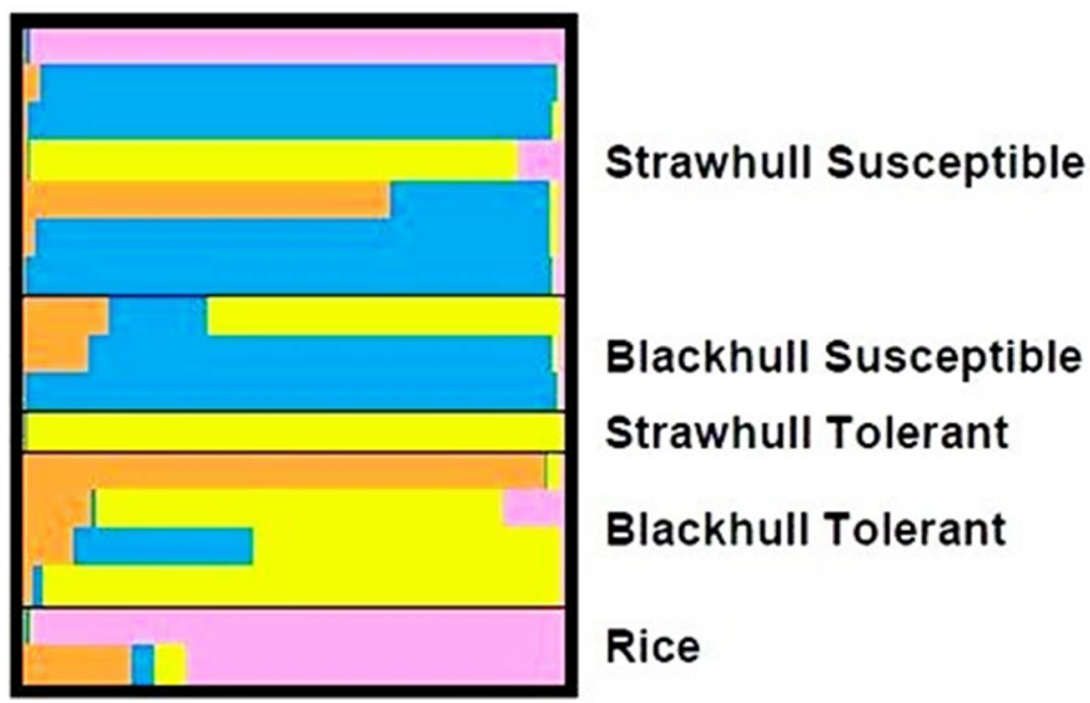

Figure 3. Population structure of accessions based on herbicide tolerance.

\subsection{Genetic Diversity among the Accessions with Respect to Allelopathic Potential}

The most and least allelopathic weedy rice accessions identified by Shrestha et al. (2020), allelopathic rice (PI338046, PI312777, Rondo), and commercial rice cultivars (CL163 and Rex) were included in this analysis [16]. The markers were not able to distinguish the accessions based on their allelopathic potential as distinct clustering pattern of allelopathic and non-allelopathic weedy rice accessions was not identified. Overall, the observed number of alleles (na) and effective number of alleles (ne) were 2.9 and 2.2, respectively. Nei's gene diversity (h) and Shannon's information index (I) for the entire population was 0.51 and 0.86 , respectively. The high value of $h$ and I indicates a high level of genetic diversity among the population. Based on Nei's genetic distance, clustering divided the accessions into three different clusters (Figure 4). Cluster one consisted of cultivated rice (CL163 and REX) and two non-allelopathic weedy rice accessions ALR-1 and ALR-4. Both CL163 and REX are reported to have no allelopathic potential; thus, cluster one had the least allelopathic accessions. Cluster two consisted of both the allelopathic and non-allelopathic accessions suggesting that the current markers were not linked strongly with the allelopathic potential of weedy rice. Cluster three consisted of allelopathic rice cultivars and one of the most allelopathic weedy rice accession B2, thus indicating genetic proximity among these accessions. Weedy rice accession B2 is reported to have high weed suppressive potential and interestingly it clustered with allelopathic rice; therefore, these might share similar genetic backgrounds. Although B2 allelopathic weedy rice was grouped with allelopathic rice cultivars, other allelopathic weedy rice did not belong to this cluster, indicating a lack of strong association of these markers with the genes controlling allelopathy in weedy rice. Population structure of the allelopathic and non-allelopathic weedy and cultivated rice showed that allelopathic rice and weedy rice had close genetic backgrounds; however, some of the allelopathic weedy rice also shared genetic similarities with non-allelopathic weedy rice (Figure 5). 


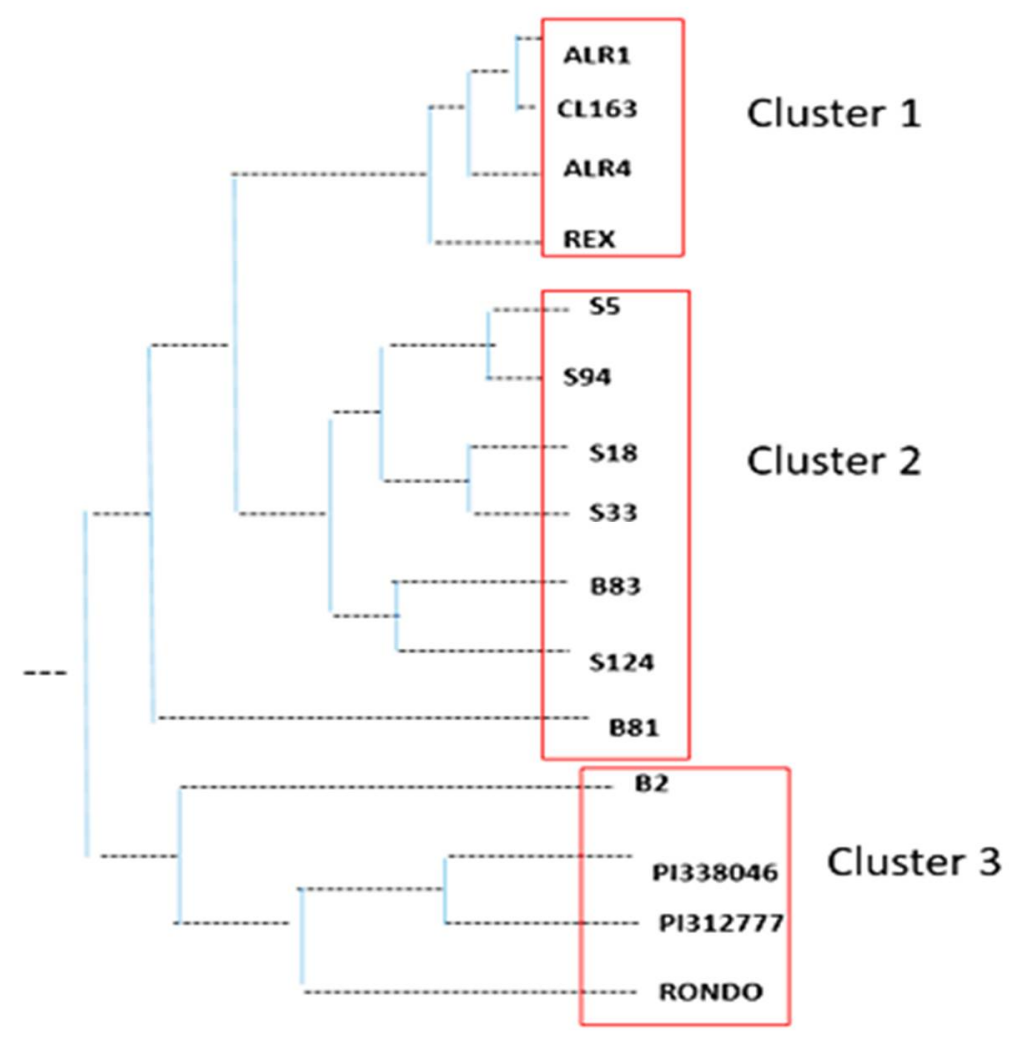

Figure 4. Dendrogram exhibiting genetic relationship among the accessions in terms of allelopathic potential. Accessions within same cluster (red box) are genetically similar as compared to the accessions in different clusters as indicated by Nei's genetic distance.

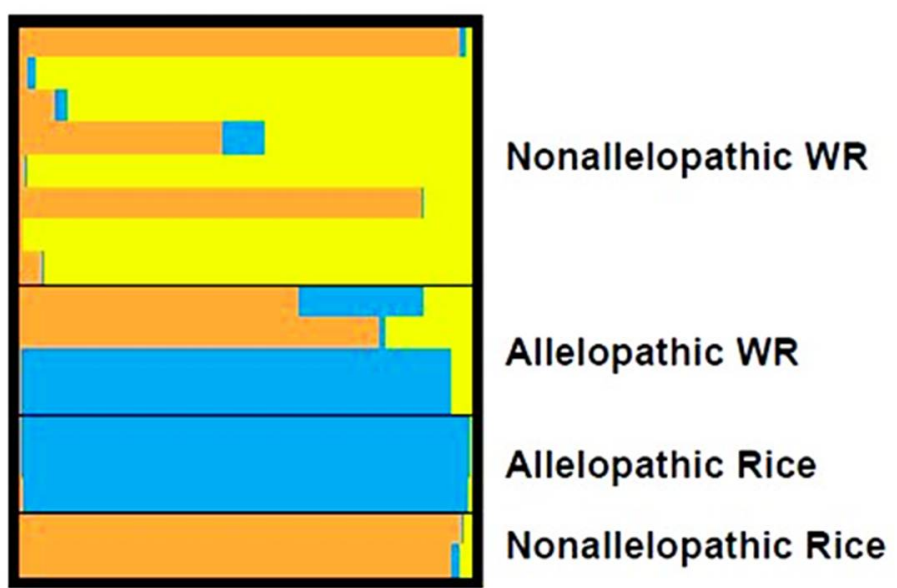

Figure 5. Population structure of accessions based on allelopathic potential.

\section{Discussion}

Fifty-four weedy rice accessions collected from different rice-growing regions of Arkansas, USA, were previously investigated for herbicide tolerance and allelopathic potential $[16,17]$. The study had identified weedy rice accessions with higher herbicide tolerance and higher weed suppressive potential. In the current study, we tried to analyze the genetic diversity in the same fifty-four weedy rice accessions along with cultivated and allelopathic rice. Nei's gene diversity measures the heterozygosity within and between the populations/individuals, and its value ranges from 0 to 1 . In our study, the Nei's genetic diversity was highest in allelopathic rice and lowest in cultivated rice. Weedy rice accessions showed Nei's genetic diversity of 0.41 , which is comparable to the genetic 
diversity of 0.31 observed in the weedy rice population from China [13]. High diversity among the weedy rice accessions might be responsible for their extensive morphological variation and adaptation in a wide range of environments [14]. The ability of weedy rice to hybridize among themselves and with the cultivated rice may have resulted in diverse genetic characteristics among the weedy rice [26]. Cultivated rice (CL 163 and REX) showed low genetic diversity of 0.24 , similar to the genetic diversity of 0.26 reported for 37 rice cultivars commonly grown in Arkansas, USA, by Shivrain et al. (2010a) [8]. However, low genetic diversity of cultivated rice might also be due to only two rice cultivars used in the study. Further, both REX and CL 163 are semi-dwarf rice cultivars released in 2014/15 and 2010, respectively, primarily for cultivating in the Southern USA [27]. As both the cultivars are developed for cultivation in similar climatic conditions and are morphologically alike, lower genetic diversity among them was expected. However, for better comparison of genetic diversity between weedy rice, allelopathic rice and cultivated rice, balanced number for each of them would be ideal.

In the current study, we hypothesized that weedy rice and allelopathic rice might have higher genetic diversity than cultivated rice. The reason behind this hypothesis was that breeding for yield and other favorable characters for decades have led to narrowing of genetic diversity in cultivated rice [28]. The genetic diversity among the allelopathic rice was relatively high (0.56). Allelopathic rice cultivars used in the study, PI312777 and PI338046, are originally from the Philippines, and Rondo is an indica rice cultivar. Rice cultivars from Asia have high genetic diversity, which might be the reason for increased genetic diversity among the allelopathic rice used in the study [29].

Results from the dendrogram based on Nei's genetic distance indicate that weedy rice and rice cultivars CL163 and REX are closely related. Weedy rice is well adapted to flourish in the cultivated rice fields under human disturbances. As the weedy rice and cultivated rice are conspecific, gene flow from cultivated rice to weedy rice is possible [30]. The frequency of gene flow from rice cultivar (Minghui-63) to weedy rice accessions ranged from 0.011 to $0.046 \%$ [31]. As weedy rice has highly similar morphological characters with cultivated rice, the chances of gene flow between cultivated rice and weedy rice flowering simultaneously are considerably high. In such a case, genes from rice cultivars can be incorporated in the weedy rice gene pool, which might be the reason for the shorter genetic distance between the weedy rice and cultivated rice. This information suggests that weedy rice can serve as a valuable source of genetic diversity in rice improvement programs as it offers low/no genetic barrier between the two. However, the fact that weedy rice and rice are closely related to each other calls for greater attention in managing weedy rice in rice fields as high similarity among the two might create hindrance in controlling weedy rice in rice fields.

The genetic comparison of the herbicide-tolerant and susceptible weedy rice and commercial rice lines reveal that the most herbicide sensitive weedy rice accession ALR4, clustered with CL163 and REX (commercial rice lines). The single cluster of cultivated rice and herbicide-sensitive weedy rice indicates close similarity. ALR4 is a brown hull accession, and studies by Shivrain et al. (2010a) showed that brown hull accessions share a closer genetic background with cultivated rice, which may be the reason behind them clustering together in the dendrogram [8]. Further, the grouping of accession B2, which has a high tolerance to glyphosate, into a distinct cluster signifies high genetic diversity in weedy rice accessions. Accession B2 is black-hulled accession collected from Grand Prairie, AR. Weedy rice accessions from Grand Prairie are more dormant than from other locations like the White River, AR [32]. Accession B2, because of its higher dormancy period, may have been able to escape the herbicide treatments and hence survive with the rice crops in the field. This might have allowed gene flow between the cultivated rice and B2, leading to genetic changes in B2 with time. Thus, the late-emerging weedy rice seedling that grows simultaneously with cultivated rice could have a high potential of cross-pollination and introgression, leading to genetic changes in the accession isolating it from other weedy rice populations. The clustering of the accessions was associated 
with herbicide tolerance as all the herbicide-tolerant and herbicide-susceptible accessions grouped separately, implying diverse genetic backgrounds of tolerant and susceptible accessions. In the current study, allelopathic and non-allelopathic weedy rice accessions did not cluster separately. Allelopathy is a highly complex trait and may be associated with a minor gene effect that would not have been captured by a limited number of markers used in the current study.Additionally, in the current study only a limited number of weedy rice accessions $(n=54)$ were sampled. It is possible that this number of accession were not able to represt the wide genetic diversity present in weedy rice $[8,9]$. In the future, it is necessary to use a larger sample size, greater number of markers or employ high-throughput sequencing techniques to capture the genetic variance associated with allelopathy to get insights into the genetic basis of this trait in weedy rice.

\section{Conclusions}

Weedy rice belongs to the same genus and species as the cultivated rice but is more competitive than cultivated rice and can flourish in extreme environmental conditions where the cultivated rice does not perform well. Weedy rice with high herbicide tolerance and allelopathic potential have been identified but not genetically explored. The present study used 30 SSR primers to access the genetic diversity among these accessions and the molecular mechanism behind these competitive traits. Herbicide tolerance was associated with the markers irrespective of their hull color, while allelopathic potential did not show a strong association with the molecular markers used in the study. In the future, the application of whole-genome sequencing tools and genotyping by sequencing (GBS) to identify variants associated with allelopathy will help understand the genetic mechanisms of allelopathy in weedy rice.

Supplementary Materials: The following are available online at https:/ /www.mdpi.com/article/ 10.3390/d14010044/s1, Table S1: List of 54 weedy rice accessions used for genotyping study, along with the herbicide tolerant and allelopathic rice identified in the study by Shrestha et al. 2019, Shrestha et al. 2020 [16,17]. Table S2: Information of 30 SSR markers used for genetic analysis in the current study.

Author Contributions: Conceptualization, T.M.T. and S.S. (Swati Shrestha); methodology, S.S. (Swati Shrestha) and S.S. (Shandrea Stallworth); formal analysis, G.S.; writing — original draft preparation, S.S. (Swati Shrestha); writing-review and editing, T.M.T., S.S. (Swati Shrestha) and E.D.R.; funding acquisition, T.M.T. All authors have read and agreed to the published version of the manuscript.

Funding: This research was funded by the Special Research Initiative Grant sponsored by the Mississippi Agricultural and Forestry Experiment Station and is based upon work that is supported by the National Institute of Food and Agriculture, U.S. Department of Agriculture, Hatch project under accession number 230100.

Institutional Review Board Statement: Not applicable.

Informed Consent Statement: Not applicable.

Data Availability Statement: Not applicable.

Conflicts of Interest: The authors declare no conflict of interest.

\section{References}

1. Singh, V.; Zhou, S.; Ganie, Z.; Valverde, B.; Avila, L.; Marchesan, E.; Merotto, A.; Zorrilla, G.; Burgos, N.; Norsworthy, J.; et al. Rice Production in the Americas. In Rice Production Worldwide; Springer International Publishing: Berlin/Heidelberg, Germany, 2017; pp. 137-168.

2. Allston, R.F. The Rice Plant; University of Michigan, Humanities Text Initiative: Ann Arbor, MI, USA, 1846.

3. Hoagland, R.E.; Paul, R.N. A Comparative SEM Study of Red Rice and Several Commerical Rice (Oryza sativa) Varieties. Weed Sci. 1978, 26, 619-625. [CrossRef]

4. $\quad$ Burgos, N.R.; Norsworthy, J.; Scott, R.C.; Smith, K.L. Red Rice (Oryza sativa) Status after 5 Years of Imidazolinone-Resistant Rice Technology in Arkansas. Weed Technol. 2008, 22, 200-208. [CrossRef] 
5. $\quad$ Burgos, N.R.; Singh, V.; Tseng, T.-M.P.; Black, H.; Young, N.D.; Huang, Z.; Hyma, K.E.; Gealy, D.R.; Caicedo, A.L. The Impact of Herbicide-Resistant Rice Technology on Phenotypic Diversity and Population Structure of United States Weedy Rice. Plant Physiol. 2014, 166, 1208-1220. [CrossRef]

6. Shivrain, V.K.; Burgos, N.R.; Gealy, D.R.; A Sales, M.; Smith, K.L. Gene flow from weedy red rice (Oryza sativa L.) to cultivated rice and fitness of hybrids. Pest Manag. Sci. 2009, 65, 1124-1129. [CrossRef]

7. Gealy, D. Gene Movement between Rice (Oryza sativa) and Weedy Rice (Oryza sativa)—A U.S. Temperate Rice Perspective. Crop Feral. Volunt. 2005, 2, 323-354.

8. Shivrain, V.K.; Burgos, N.R.; Agrama, H.A.; Lawton-Rauh, A.; Lu, B.; Sales, M.A.; Boyett, V.; Gealy, D.R.; Moldenhauer, K.A.K. Genetic diversity of weedy red rice (Oryza sativa) in Arkansas, USA. Weed Res. 2010, 50, 289-302. [CrossRef]

9. Shivrain, V.K.; Burgos, N.R.; Scott, R.C.; Gbur, E.E., Jr.; Estorninos, L.E., Jr.; McClelland, M.R. Diversity of weedy red rice (Oryza sativa L.) in Arkansas, USA in relation to weed management. Crop Prot. 2010, 29, 721-730. [CrossRef]

10. Tseng, T.-M.; Shivrain, V.K.; Lawton-Rauh, A.; Burgos, N.R. Dormancy-linked Population Structure of Weedy Rice (Oryza sp.). Weed Sci. 2018, 66, 331-339. [CrossRef]

11. Noldin, J.A.; Chandler, J.M.; McCauley, G.N. Red Rice (Oryza sativa) Biology. I. Characterization of Red Rice Ecotypes. Weed Technol. 1999, 13, 12-18. [CrossRef]

12. Cohn, M.A.; Hughes, J.A. Seed Dormancy in Red Rice (Oryza sativa) I. Effect of Temperature on Dry-Afterripening. Weed Sci. 1981, 29, 402-404. [CrossRef]

13. Cao, Q.; Lu, B.-R.; Xia, H.; Rong, J.; Sala, F.; Spada, A.; Grassi, F. Genetic Diversity and Origin of Weedy Rice (Oryza sativa f. spontanea) Populations Found in North-eastern China Revealed by Simple Sequence Repeat (SSR) Markers. Ann. Bot. 2006, 98 , 1241-1252. [CrossRef] [PubMed]

14. Liu, Y.; Qi, X.; Gealy, D.R.; Olsen, K.M.; Caicedo, A.L.; Jia, Y. QTL Analysis for Resistance to Blast Disease in U.S. Weedy Rice. Mol. Plant-Microbe Interact. 2015, 28, 834-844. [CrossRef] [PubMed]

15. Ziska, L.H.; McClung, A. Differential Response of Cultivated and Weedy (Red) Rice to Recent and Projected Increases in Atmospheric Carbon Dioxide. Agron. J. 2008, 100, 1259-1263. [CrossRef]

16. Shrestha, S.; Sharma, G.; Burgos, N.R.; Tseng, T.-M. Competitive ability of weedy rice: Toward breeding weed-suppressive rice cultivars. J. Crop. Improv. 2020, 34, 455-469. [CrossRef]

17. Khanh, T.D.; Chung, M.I.; Xuan, T.D.; Tawata, S. The Exploitation of Crop Allelopathy in Sustainable Agricultural Production J. Agron. Crop. Sci. 2005, 191, 172-184. [CrossRef]

18. Ma, Y.; Zhang, M.; Li, Y.; Shui, J.; Zhou, Y. Allelopathy of rice (Oryza sativa L.) root exudates and its relations with Orobanche cumana Wallr. and Orobanche minor Sm. germination. J. Plant Interact. 2014, 9, 722-730. [CrossRef]

19. Shrestha, S.; Sharma, G.; Burgos, N.R.; Tseng, T.-M. Response of weedy rice (Oryza spp.) germplasm from Arkansas to glyphosate, glufosinate, and flumioxazin. Weed Sci. 2019, 67, 303-310. [CrossRef]

20. Tseng, T.M. Genetic Diversity of Seed Dormancy and Molecular Evolution of Weedy Red Rice. Ph.D. Dissertation, University of Arkansas, Fayetteville, AR, USA, 2013.

21. Doyle, J.J. A rapid DNA isolation procedure for small quantities of fresh leaf tissue. Phytochem. Bull. Bot. Soc. Am. 1987, 19, 11-15.

22. McCouch, S.R.; Teytelman, L.; Xu, Y.; Lobos, K.B.; Clare, K.; Walton, M.; Fu, B.; Maghirang, R.; Li, Z.; Xing, Y.; et al. Development and Mapping of 2240 New SSR Markers for Rice (Oryza sativa L.). DNA Res. 2002, 9, 199-207. [CrossRef]

23. Yang, G.P.; Maroof, M.S.; Xu, C.G.; Zhang, Q.; Biyashev, R.M. Comparative analysis of microsatellite DNA polymorphism in landraces and cultivars of rice. Mol. Genet. Genom. 1994, 245, 187-194. [CrossRef]

24. Buntjier, J.B. Cross Checker; Wageningen University: Wageningen, The Netherlands, 1999.

25. Pritchard, J.K.; Stephens, M.; Donnelly, P. Inference of population structure using multilocus genotype data. Genetics 2000, 155, 945-959. [CrossRef]

26. Londo, J.P.; Schaal, B.A. Origins and population genetics of weedy red rice in the USA. Mol. Ecol. 2007, 16, 4523-4535. [CrossRef] [PubMed]

27. Redona ED CL163: A New High-Amylose Content Clearfield Rice Variety. Available online: http://drec.msstate.edu/sites/ default/files /cl163\%20a\%20new\%20high-amylose\%20content\%20clearfield-rice\%20variety.pdf (accessed on 8 September 2018).

28. Sun, C.Q.; Wang, X.K.; Li, Z.C.; Yoshimura, A.; Iwata, N. Comparison of the genetic diversity of common wild rice (Oryza rufipogon Griff.) and cultivated rice (O. sativa L.) using RFLP markers. Theor. Appl. Genet. 2001, 102, 157-162. [CrossRef]

29. Lapitan, V.C.; Brar, D.S.; Abe, T.; Redoña, E.D. Assessment of Genetic Diversity of Philippine Rice Cultivars Carrying Good Quality Traits using SSR Markers. Breed. Sci. 2007, 57, 263-270. [CrossRef]

30. Xia, H.-B.; Wang, W.; Xia, H.; Zhao, W.; Lu, B.-R. Conspecific Crop-Weed Introgression Influences Evolution of Weedy Rice (Oryza sativa f. spontanea) across a Geographical Range. PLoS ONE 2011, 6, e16189. [CrossRef]

31. Chen, L.J.; Lee, D.S.; Song, Z.P.; Suh, H.S.; LU, B.R. Gene flow from cultivated rice (Oryza sativa) to its weedy and wild relatives. Ann. Bot. 2004, 93, 67-73. [CrossRef]

32. Tseng, T.M.; Burgos, N.R.; Shivrain, V.K.; Alcober, E.A.; Mauromoustakos, A. Inter-and intrapopulation variation in dormancy of Oryza sativa (weedy red rice) and allelic variation in dormancy-linked loci. Weed Res. 2013, 53, 440-451. [CrossRef] 